\title{
Contribution of the Interdecadal Pacific Oscillation to the Recent Abrupt Decrease in Tropical Cyclone Genesis Frequency over the Western North Pacific since 1998
}

\author{
JIUWEI ZHAO \\ Pacific Typhoon Research Center, Key Laboratory of Meteorological Disaster, Ministry of Education, Nanjing \\ University of Information Science and Technology, Nanjing, China, and International Pacific Research Center, \\ and Department of Atmospheric Sciences, School of Ocean and Earth Science and Technology, University of \\ Hawai'i at Mānoa, Honolulu, Hawaii \\ RUIFEN ZHAN \\ Shanghai Typhoon Institute, China Meteorological Administration, Shanghai, China \\ YUQING WANG \\ Pacific Typhoon Research Center, Key Laboratory of Meteorological Disaster, Ministry of Education, Nanjing \\ University of Information Science and Technology, Nanjing, China, and International Pacific Research \\ Center, and Department of Atmospheric Sciences, School of Ocean and Earth Science and Technology, \\ University of Hawai'i at Mānoa, Honolulu, Hawaii
}

HAIMING XU

Pacific Typhoon Research Center, Key Laboratory of Meteorological Disaster, Ministry of Education, Nanjing University of Information Science and Technology, Nanjing, China

(Manuscript received 4 April 2018, in final form 29 July 2018)

\begin{abstract}
Previous studies have documented an abrupt decrease of tropical cyclone (TC) genesis frequency over the western North Pacific (WNP) since 1998. In this study, results from an objective clustering analysis demonstrated that this abrupt decrease is primarily related to the decrease in a cluster of TCs (C1) that mostly formed over the southeastern WNP, south of $15^{\circ} \mathrm{N}$ and east of the Philippines, and possessed long tracks. Further statistical analyses based on both best track TC data and global reanalysis data during 1980-2015 revealed that the genesis of C1 TCs was significantly modulated by the interdecadal Pacific oscillation (IPO), whose recent negative phase since 1998 corresponded to a La Niña-like sea surface temperature anomaly (SSTA) pattern, which strengthened the Walker circulation in the tropical Pacific and weakened the WNP monsoon trough, suppressing genesis of $\mathrm{C} 1 \mathrm{TCs}$ in the southeastern WNP and predominantly contributing to the decrease in TC genesis frequency over the entire WNP basin. These findings were further confirmed by results from similar analyses based on longer observational datasets and also the outputs from a 500-yr preindustrial general circulation model experiment using the Geophysical Fluid Dynamics Laboratory (GFDL) Coupled Model, version 3. Additional analysis indicates that the decrease in C1 TC genesis frequency in the recent period was dominated during August-October, with the largest decrease in October.
\end{abstract}

\section{Introduction}

Variabilities of tropical cyclone (TC) activity on various time scales over the western North Pacific (WNP) and their associated physical mechanisms have been a

Corresponding author: Dr. Ruifen Zhan, zhanrf@typhoon.org.cn topic of active research for a decade or so. However, most previous studies have focused on the interannual time scale (Wang and Chan 2002; Camargo and Sobel 2005; Zhan et al. 2011a,b, 2013; Yu et al. 2016). More recent studies have shown that the interannual relationships between TC activity and other climate factors are subject to significant interdecadal changes 
(Zhan et al. 2014; Cao et al. 2016; Zhao and Wang 2016; Zhao et al. 2016). This has led to increasing attention to the study of the interdecadal/decadal variability in TC activity over the WNP in recent years [see a review by Walsh et al. (2016)].

Despite the controversy on data uncertainty of longterm changes in TC activity, an abrupt decrease in TC genesis frequency over the WNP since 1998 has been well reported based on various TC data sources (Liu and Chan 2013; Hsu et al. 2014; He et al. 2015; Wu et al. 2015; Hong et al. 2016; Takahashi et al. 2017; Hu et al. 2018; Zhang et al. 2018). However, these studies have mainly considered basinwide TC activity as a whole. TC activity over the WNP is often characterized by regional dependence. A typical example of such region dependence is the response of TC genesis location to the El NiñoSouthern Oscillation (ENSO; Chia and Ropelewski 2002; Wang and Chan 2002; Camargo et al. 2007b). A natural question arises as to whether and how the regional changes contributed to the interdecadal shift in TC activity over the WNP, such as the abrupt decrease in TC genesis frequency since 1998. Different drivers have been proposed to explain this observed decrease. Some studies have emphasized the dominant roles of the decadal change of Indo-Pacific sea surface temperature (SST) anomalies (SSTAs), such as the La Niña-like SSTA pattern in the tropical Pacific, and the Atlantic multidecadal oscillation (AMO) ( $\mathrm{Hsu}$ et al. 2014; He et al. 2015; Huangfu et al. 2017, 2018; Zhang et al. 2018). Several studies have also shown the possible influences of a change in aerosol loading and a change in climate regime on this significant decrease (Wu et al. 2015; Takahashi et al. 2017). Therefore, no consensus on the mechanisms responsible for the recent interdecadal change of WNP TC activity has been reached so far.

Although recent studies have related the interdecadal changes of WNP TC activity to SSTA over the North Atlantic (Yu et al. 2016; Zhang et al. 2018), the effects of SSTA over the Pacific should be more direct than those from the North Atlantic. Particularly, since the interdecadal Pacific oscillation (IPO) is the dominant mode in the Pacific climate variability, it must be responsible for many interdecadal changes in the Pacific basin, including the activity of Pacific TCs (Li et al. 2015). More recently, Song and Klotzbach (2018) proposed that the IPO contributed largely to the poleward migration of the annual mean location of lifetime maximum intensity of WNP TCs. Hu et al. (2018) also noticed the synchronization between the step-by-step decrease in WNP TC genesis frequency and the IPO phases. Questions arise as to whether the recent decrease in TC genesis frequency over the WNP is linked to the IPO and if so, how the IPO influenced WNP TC activity.
In this study, an objective cluster analysis method is used to identify TCs that contributed to the interdecadal change in TC activity over the WNP. This is different from previous studies, in which TCs over the WNP were often considered as a whole (Hu et al. 2018) or categorized subjectively [e.g., based on the geographic locations of TC genesis; He et al. (2015)], and thus lack of physical basis. Based on an objective clustering analysis, we will report in this study that only one cluster of TCs dominated the basin-scale interdecadal decrease in TC genesis over the WNP since 1998, which provides new insights into the understanding of physical mechanisms response for the variability of TC activity. Furthermore, we will demonstrate that this cluster was significantly dominated by the IPO. The rest of the paper is organized as follows. Section 2 describes the data used and the methodology. The interdecadal changes in WNP TC genesis frequency and in individual clusters of TCs are discussed in section 3 . The possible contribution of the IPO to the recent abrupt decrease in TC genesis frequency over the WNP is analyzed in section 4. Major findings are summarized and discussed in the last section.

\section{Data and methodology}

The best track TC dataset of the Joint Typhoon Warning Center (JTWC) was used in this study, which includes 6-hourly location of TC center (longitude and latitude) and TC maximum sustained (1-min averaged) near-surface wind speed (Vmax). We focused mainly on TCs with Vmax equal to or greater than $35 \mathrm{kt}(1 \mathrm{kt}=$ $0.51 \mathrm{~m} \mathrm{~s}^{-1}$ ) over the WNP extending from $100^{\circ} \mathrm{E}$ to the international date line in the main TC (typhoon) season [June-October (JJASO)] during 1980-2015, including a total of 700 TCs. The track density was defined as the frequency of TC occurrence in each $5^{\circ} \times 5^{\circ}$ grid box, which indicates how often TCs passed through a specific grid box.

Monthly mean SST data with $2^{\circ} \times 2^{\circ}$ horizontal resolution were derived from the National Oceanic and Atmospheric Administration (NOAA) Extended Reconstructed SST, version 4 (ERSST.v4; Huang et al. 2015). Outgoing longwave radiation (OLR) data were also obtained from NOAA. Monthly mean atmospheric data with a $2.5^{\circ} \times 2.5^{\circ}$ horizontal resolution were obtained from the National Centers for Environmental Prediction-National Center for Atmospheric Research (NCEP-NCAR) reanalysis (Kalnay et al. 1996). We also employed the ERA-Interim data (Dee et al. 2011) to confirm the regressed results derived from the NCEPNCAR reanalysis data. The output of a $500-y r$ preindustrial experiment from the Geophysical Fluid Dynamics Laboratory (GFDL) Coupled Model, version 3 
(GFDL CM3; Donner et al. 2011), was also used to confirm the influence of the IPO on the atmospheric circulation that controls TC genesis over the WNP. The vertical zonal wind shear (VZWS) was defined as the difference of zonal winds between 200 and $850 \mathrm{hPa}$ in this study, which is one of the major environmental factors affecting TC genesis over the WNP (e.g., Emanuel 1999; Wang and Chan 2002; Liu and Chan 2013; Zhan and Wang 2017).

The IPO is a multidecadal SSTA pattern with some geographical similarity to ENSO but is more symmetric about the equator and has more loadings in both the North and South Pacific (Power et al. 1999). Following Henley et al. (2015), the tripole index (TPI) was used to define the IPO index. This index is based on the differences between the SSTA averaged over the central equatorial Pacific $\left(10^{\circ} \mathrm{S}-10^{\circ} \mathrm{N}, 170^{\circ} \mathrm{E}-90^{\circ} \mathrm{W}\right)$ and the averaged SSTA in the northwest $\left(25^{\circ}-45^{\circ} \mathrm{N}, 140^{\circ} \mathrm{E}-\right.$ $\left.145^{\circ} \mathrm{W}\right)$ and southwest $\left(50^{\circ}-15^{\circ} \mathrm{S}, 150^{\circ} \mathrm{E}-160^{\circ} \mathrm{W}\right)$ Pacific.

An objective clustering technique developed by Gaffney et al. (2007) was utilized in our study to classify the WNP TCs into three distinct clusters considering TC tracks, which has also been used in previous studies to study the interannual variability and trend of TC activity (Camargo et al. 2007a,b; Kim and Seo 2016; Mei and Xie 2016). This curve clustering method ( $k$-means method) based on the linearly regressed finite mixture model was used to represent a data distribution as a convex linear combination of component density functions. One of the key features of the mixture model is its capability to simulate highly non-Gaussian and possibly multimodal densities. In this study, the component densities modeled longitudinal and latitudinal positions of a TC versus time in the quadratic polynomial regression functions. The latitude and longitude positions were treated as conditionally independent to feed the model, and thus the complete function for a TC track was a product of these two. Each TC track was assumed to be generated by one of three different regression models, each having its own shape parameters. The clustering problem first needed to learn the parameters of all three models given the TC track, and then infer which of the three models most likely reproduced that track. In other words, the assigned cluster had the highest posterior probability given the track. An expectation maximization (EM) algorithm was also introduced for learning model parameters. This algorithm iterated through the expectation ("E") and maximization ("M") steps until it converged. In our work, the algorithm was started through selecting a set of membership weights randomly and then executing $\mathrm{M}$ step. The iterative convergence threshold was set to $10^{-8}$ and the best solution was obtained from 10 starts of EM was chosen to avoid poor
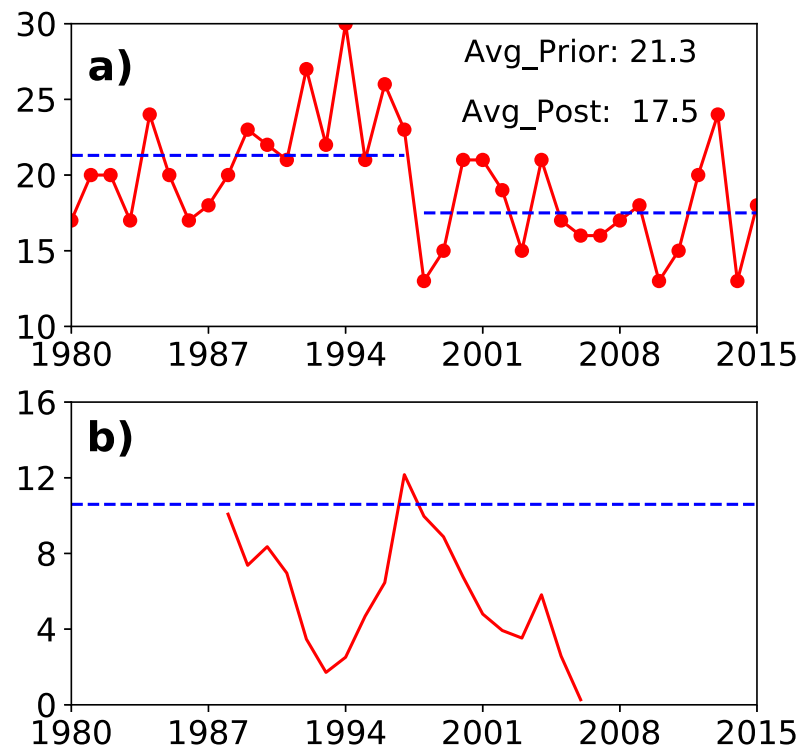

FIG. 1. Time series of (a) total TC genesis frequency over the WNP during the typhoon season (JJASO) from 1980 to 2015 and (b) the corresponding Lepage test. The dashed blue lines in (a) represent averages in the prior (1980-97) and the recent (19982015) periods, respectively. The dashed blue line in (b) represents the $95 \%$ confidence level.

local maxima in the parameter space. The detailed parameter setting of the clustering model can also be found in Camargo et al. (2007a), Gaffney et al. (2007), and Mei and Xie (2016).

In addition, we used the Lepage test (Lepage 1971) with a 9-yr window to test significance of the interdecadal shift. We conducted the regression analyses to examine the responses of large-scale environments to the IPO. Before the regression analyses were conducted, the interannual variability of all variables was removed using the nine-point Gaussian-type filter. The corresponding significance was tested based on Student's $t$ test after adjusting the degree of freedom following Bretherton et al. (1999).

\section{Interdecadal change in TC genesis frequency and the associated TC clusters}

Figure 1a shows the time series of TC genesis frequency over the entire WNP basin (hereafter total TC genesis frequency) during 1980-2015. The most prominent feature is an abrupt change around 1998. The averaged JJASO TC genesis frequency reached 21.3 during 1980-97 (hereafter prior period) but dropped to 17.5 during 1998-2015 (hereafter recent period). The difference between these two periods is significant at the $95 \%$ confidence level based on the Student's $t$ test. The Lepage test also confirms such an interdecadal shift 


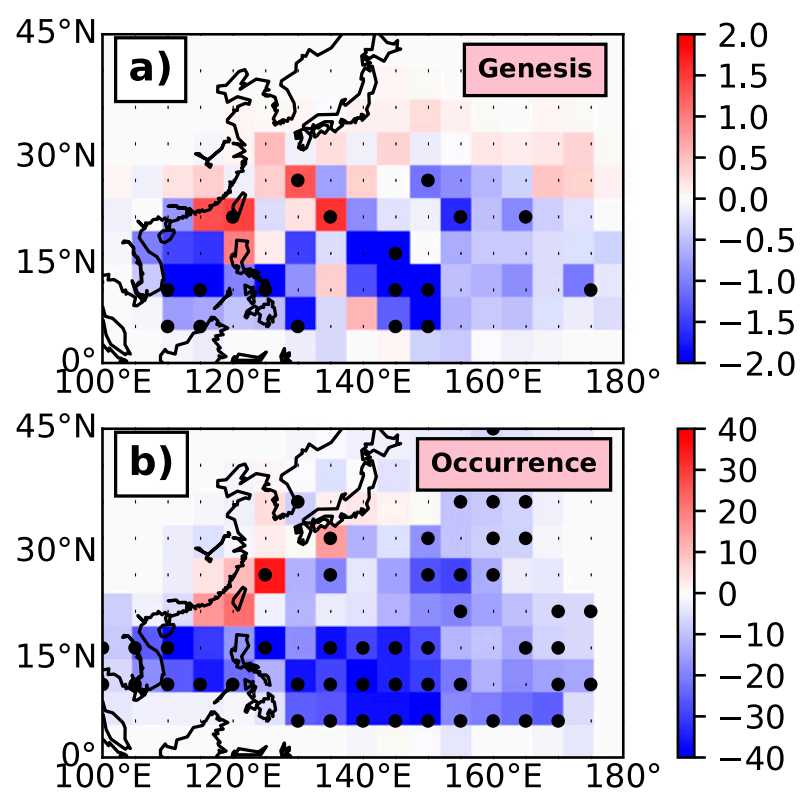

FIG. 2. Composite differences in frequencies of (a) TC genesis and (b) TC occurrences between the recent and prior periods (counts per decade). Areas where the differences are statistically significant at the $95 \%$ confidence level are shown in black dots based on the Student's $t$ test.

around 1998, which is significant at the $95 \%$ confidence level (Fig. 1b). This interdecadal shift has been reported in previous studies using various TC best track datasets (Liu and Chan 2013; Hsu et al. 2014; He et al. 2015; Wu et al. 2015; Takahashi et al. 2017; Hu et al. 2018) and using numerical models (Zhang et al. 2018), suggesting that this shift is considerably robust.

Figure 2 shows the composite differences in frequencies of TC genesis and TC occurrence between the recent and prior periods. Here the frequencies of TC genesis and TC occurrence were binned in each $5^{\circ} \times 5^{\circ}$ grid box. The former shows how many TCs formed in a specific grid box, while the latter indicates how often TCs passed through a specific grid box. In the recent period, there was an increase in TC genesis over the coastal region of East Asia and a decrease in other regions over the WNP (Fig. 2a). The decrease in TC genesis mainly occurred in two regions: one was centered at around $145^{\circ} \mathrm{E}$ and the other was over the South China Sea (SCS), both mainly south of $20^{\circ} \mathrm{N}$. The TC occurrence frequency shows similar spatial variations (Fig. 2b), with a significant decrease in the southeastern WNP and the SCS and a significant increase along the East Asian coastal region as recently discussed by Mei and Xie (2016) and Zhao et al. (2018).

Since TC activity showed a distinct spatial heterogeneity, it is our interest to examine whether any specific cluster of TCs dominantly contributed to the interdecadal shift in TC genesis frequency over the WNP basin around 1998. For this purpose, we conducted the clustering analysis outlined in section 2 . We categorized 700 TCs over the WNP in JJASO during 1980 2015 into three clusters (Fig. 3). It should be mentioned that Camargo et al. (2007a,b) and Mei and Xie (2016) grouped WNP TCs into seven and four clusters, respectively. Camargo et al. (2007a,b) also tested how the number of clusters changing from two to nine affected the final regression curves and found two basic TC behaviors: "straight movers" and "recurved movers," same as those found in Harr and Elsberry $(1991,1995)$. Some clusters had similar regression curves, either straight or curved, and were related to the different phases of ENSO (Camargo et al. 2007a,b). Here, we found three distinct clusters, and each had its own main characteristics in terms of its genesis locations and predominant tracks.

Figure 3 shows the tracks and genesis locations of the three distinct clusters of WNP TCs. Note that the red curves (dots) in Fig. 3 stand for TC tracks (genesis locations) before 1998 while the blue ones are for those after 1998, and the yellow curves (triangles) represent the average tracks (genesis locations) for the three clusters in the prior period while the black curves (triangles) represent those in the recent period. Cluster 1 (C1; Figs. 3a and 3b) constitutes 170 TCs or around $24.3 \%$ of all 700 TCs in the basin, while cluster 2 (C2; Figs. 3c and 3d) and cluster 3 (C3; Figs. 3e and 3f) account for $37.1 \%$ and $38.6 \%$, respectively. Most of $\mathrm{C} 1$ TCs formed in the southeast quadrant south of $15^{\circ} \mathrm{N}$ over the WNP and recurved northeastward along the East Asian coast, C2 TCs mostly formed north of $15^{\circ} \mathrm{N}$ and moved northward, and C3 TCs mostly formed either in the SCS or in the western WNP and moved westward and entered the SCS. In addition, C1 TCs had longer tracks and thus often possessed longer lifetime and stronger intensity than either $\mathrm{C} 2$ or $\mathrm{C} 3 \mathrm{TCs}$. In the recent period, the average tracks of $\mathrm{C} 1$ and $\mathrm{C} 2 \mathrm{TCs}$ moved more westward than those in the prior period, suggesting a tendency of higher threat to East Asia in the recent period, which deserves further investigation in a future study.

Figure 4 shows the time series of genesis frequencies of the three distinct clusters during the typhoon season from 1980 to 2015 and the corresponding Lepage test. Consistent with the total TC genesis frequency (Fig. 1), the $\mathrm{C} 1 \mathrm{TC}$ genesis frequency displays a significant interdecadal shift around 1998; namely, an abrupt decrease from 6.8 on average in the prior period to only 2.6 in the recent period (Fig. 4a). The Lepage test also confirms that the $\mathrm{C} 1 \mathrm{TC}$ genesis frequency did experience an interdecadal shift around 1998, significant at the 

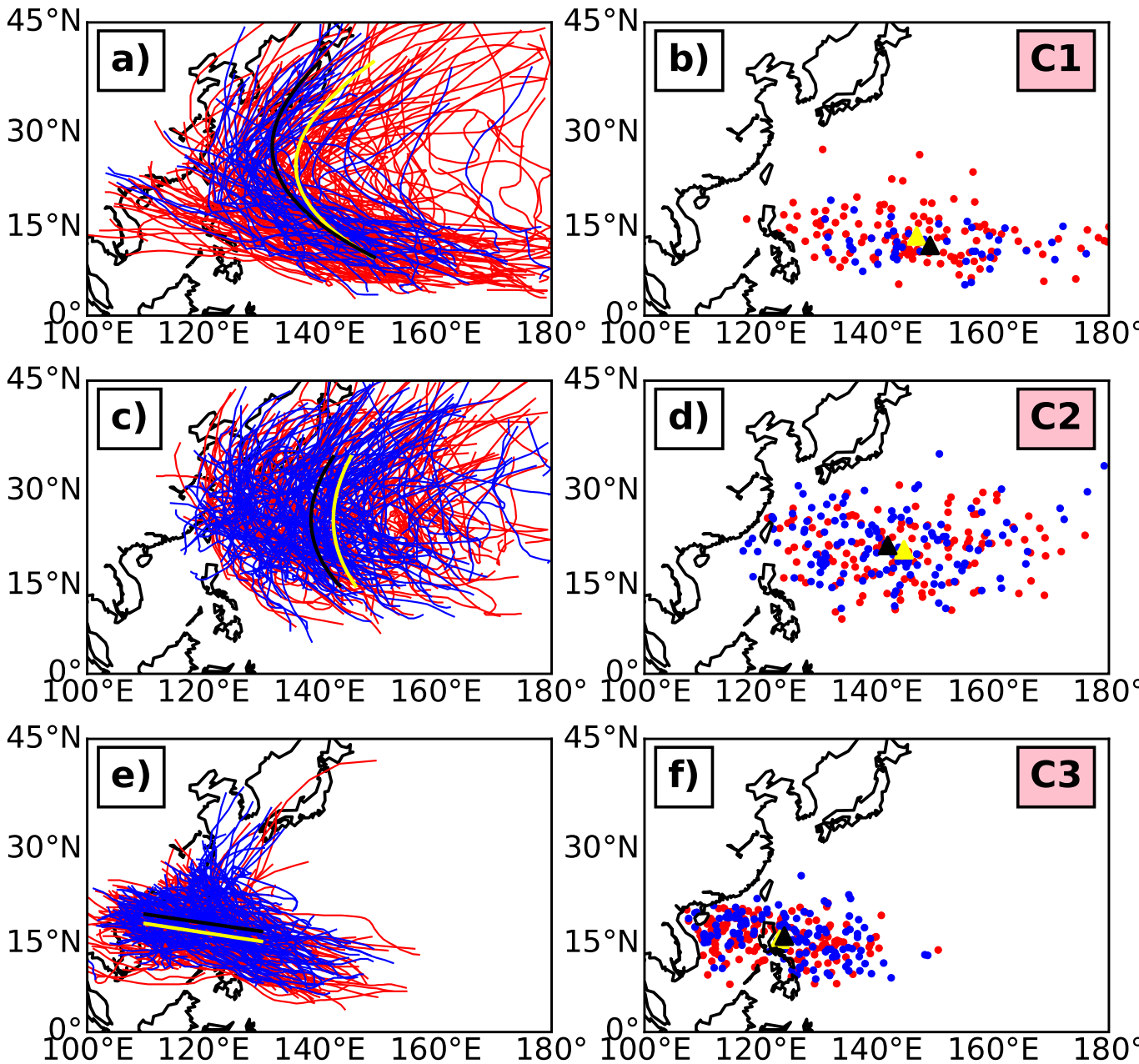

FIG. 3. (a),(c),(e) Tracks and (b),(d),(f) genesis locations of the three distinct clusters of TCs over the WNP in the typhoon season during 1980-2015: (top) C1, (middle) C2, and (bottom) C3. The red and blue curves (dots) refer to the tracks (genesis locations) in the prior and recent periods, respectively. The yellow and black curves (triangles) refer to the averages in the prior and recent periods, respectively.

95\% confidence level (Fig. 4b). In contrast, there is not a significant interdecadal shift in either $\mathrm{C} 2$ or $\mathrm{C} 3 \mathrm{TC}$ genesis frequency during the studied period (Figs. 4c-f). This strongly suggests that it is the abrupt decrease in the C1 TC genesis frequency that dominated the interdecadal decrease in the total TC genesis frequency over the WNP since 1998. The consistence can also be clearly seen in the spatial distributions of TC genesis and occurrence frequencies (Fig. 5). The differences in $\mathrm{C} 1$ genesis and occurrence frequencies between the recent and prior periods show spatial patterns similar to those of total TCs (Fig. 2), with a significant decrease in the tropical WNP and the SCS. This further demonstrates that the decrease in the frequencies of genesis and occurrence of total TCs since 1998 was mainly contributed to by the decrease in the frequencies of genesis and occurrence of C1 TCs. In sharp contrast, the mean C2 and C3 TC tracks, as well as their genesis locations, only show a slight westward and northward shift, which is not statistically significant (Figs. 3c-f).

\section{Impact of the IPO on WNP TC activity}

Many studies have shown that the IPO changed its phase from positive to negative around 1998 (Henley et al. 2015; Meehl et al. 2016; Song and Klotzbach 2018). The recent negative phase of the IPO is characterized by a La Niña-like SSTA pattern in the tropical Pacific, with more significant warming in the northwest $\left(25^{\circ}-45^{\circ} \mathrm{N}, 140^{\circ} \mathrm{E}-\right.$ $\left.145^{\circ} \mathrm{W}\right)$ and southwest $\left(50^{\circ}-15^{\circ} \mathrm{S}, 150^{\circ} \mathrm{E}-160^{\circ} \mathrm{W}\right)$ Pacific (Fig. 6a). In this section, we will demonstrate that the recent negative IPO phase suppressed C1 TC genesis, which contributed significantly to the recent abrupt decrease in the total TC genesis frequency over the WNP. 

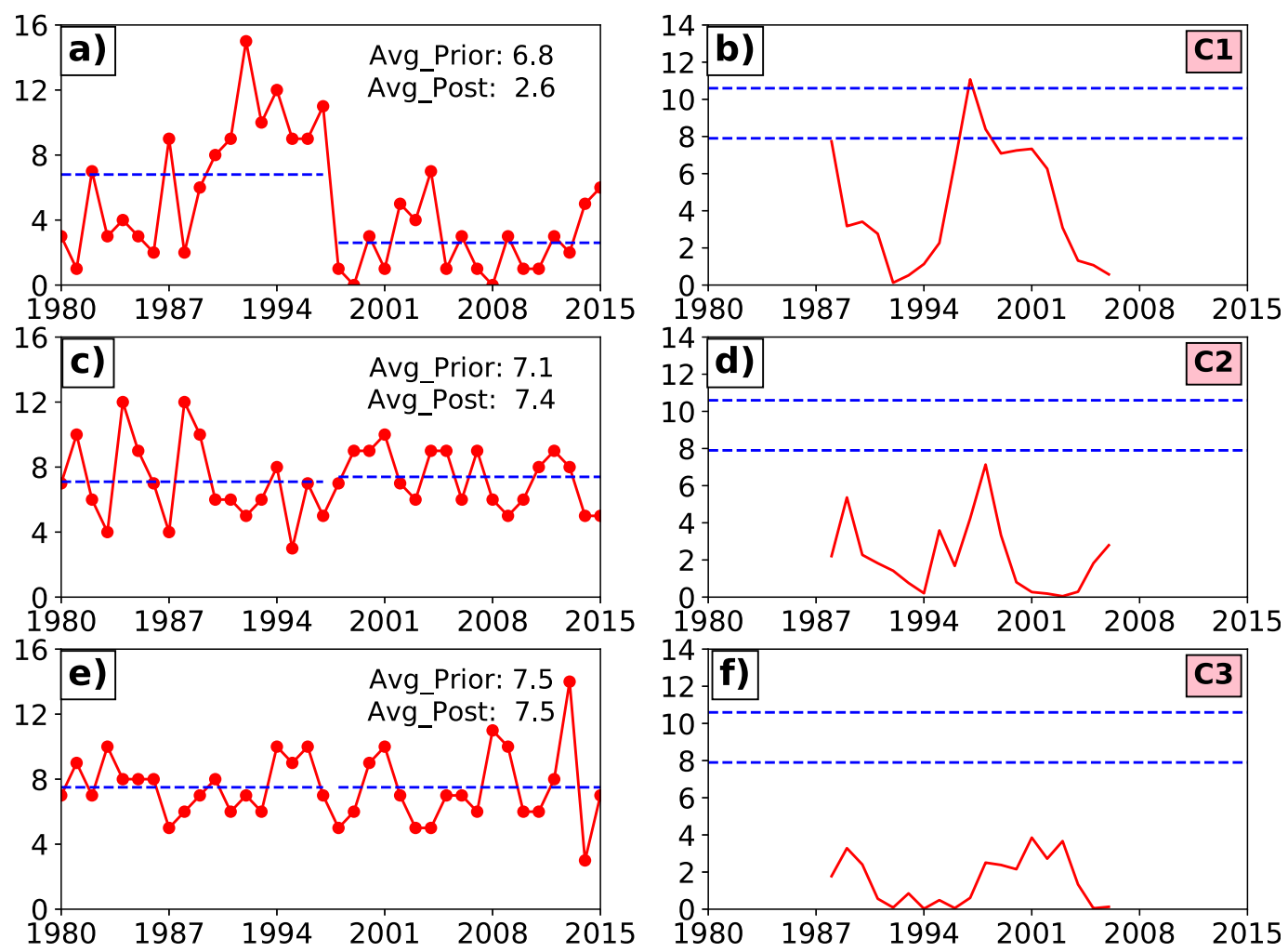

FIG. 4. As in Fig. 1, but for (a),(b) C1; (c),(d) C2; and (e),(f) C3 TCs. The blue lines in (a), (c), and (e) stand for the average values of TC genesis frequency for three cluster TCs between the prior and recent periods. The top and bottom blue lines in (b), (d), and (f) represent significant at the $95 \%$ and $90 \%$ confidence levels based on the Lepage test, respectively.

Figure $6 \mathrm{~b}$ shows the normalized time series of the IPO index, the $\mathrm{C} 1$, and total TC genesis frequencies with the interannual variability removed. The normalized genesis frequency of total TCs is highly correlated with the IPO with the correlation coefficient of 0.68 , which is significant at the $95 \%$ confidence level based on the Student's $t$ test with the degree of freedom being adjusted to 12. However, the unfiltered time series shows insignificant negative correlation with the correlation coefficient of only -0.17 (Table 1 ). This strongly suggests that the total TC genesis frequency is significantly modulated by the IPO only on the interdecadal time scale. We also calculated the correlations between the IPO index and the normalized genesis frequencies of different cluster TCs for the prior, recent, and whole time periods on the interannual time scale, as well as for the whole period on the interdecadal time scale, with the results given in Table 1.

On the interdecadal time scale, the genesis frequency of C1 TCs is still highly correlated with the IPO index, with the correlation coefficient as high as 0.69 , which is significant at the $95 \%$ confidence level. However, the correlation between the genesis frequency of $\mathrm{C} 2 \mathrm{TCs}$ and the IPO index is negative and statistically insignificant (Table 1). The genesis frequency of C3 TCs shows no significant correlation with the IPO on either the interannual or interdecadal time scales, indicating that the variability of $\mathrm{C} 3 \mathrm{TCs}$ is controlled by factors other than the IPO. The results thus demonstrate that the abrupt decrease of $\mathrm{C} 1 \mathrm{TCs}$, which dominated the interdecadal decrease of the basin-scale TCs, was induced by the phase change of the IPO. However, C2 TCs contributed insignificantly to the interdecadal change of the basin-scale TC genesis frequency, in sharp contrast to the interannual variability.

On the interannual time scale, the genesis frequency of $\mathrm{C} 1 \mathrm{TCs}$ is positively correlated with the unfiltered IPO index for all periods (the prior, recent, and whole periods), all significant at the $95 \%$ confidence level. The C2 TC genesis frequency is negatively correlated with the unfiltered IPO index, also significant at the $95 \%$ confidence level. This opposite interannual relationship with the IPO between $\mathrm{C} 1$ and $\mathrm{C} 2 \mathrm{TCs}$ mainly reflects the southeast-northwest (or north-south) shift of TC genesis locations resulting from the interannual variability of ENSO (Chia and Ropelewski 2002; Wang and Chan 

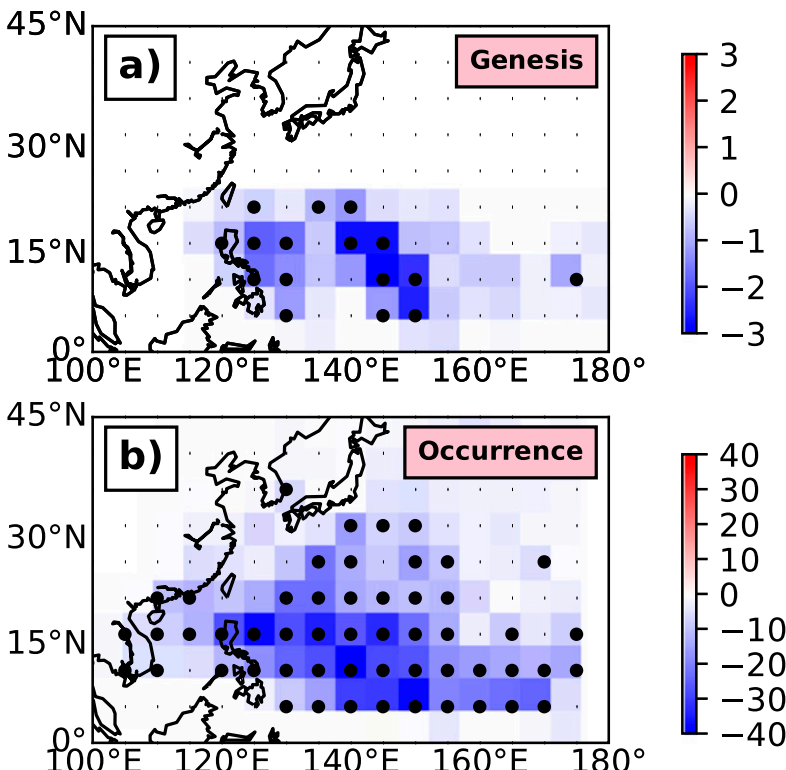

FIG. 5. As in Fig. 2, but for C1 TCs only.

2002) and the tropical-subtropical Sverdrup transport during the ENSO charge and discharge processes (Sverdrup 1947; Jin 1997). This also explains why the correlation between the ENSO (Niño-3.4 and also the IPO) index and the total TC genesis frequency is statistically insignificant on the interannual time scale (Table 1). This demonstrates the advantage in classifying TCs over the WNP into three distinct clusters to the study of the interannual and interdecadal variabilities of TC activity in the basin.

The above analyses were based on the best track TC data and observed SST data in the period 1980-2015 mainly because the TC best track data are considered to be less reliable before 1979 and often not included in analyses making major conclusions. Nevertheless, an extension of the analysis to include data in earlier years was also performed for a reference (Fig. 7). We repeated the same cluster analysis for WNP TCs during a much longer time period from 1945 to 2015 and calculated the correlation coefficients, with the results given in Table 1 as well. In general, the correlation coefficients between the IPO index and, respectively, frequencies of total TCs and of TCs in different clusters for the period of 19452015 are all similar to those for the period of 1980-2015. This strongly suggests that although the TC best track data before the satellite era (particularly before the 1960s) are less reliable, the overall interdecadal variability seems not to be significantly affected by the data quality.

Since only C1 TCs dominated the interdecadal shift of the total TC genesis frequency, the following discussion will focus on how the IPO affected the C1 TC activity over the WNP. Figure 8 shows the seasonal mean lowlevel winds and anomalous OLR fields in the typhoon season for the prior and recent periods. It can be seen that the SCS and WNP monsoon trough in the prior period extended from the SCS to west of $160^{\circ}$ E over the WNP, which corresponded with the west-east negative
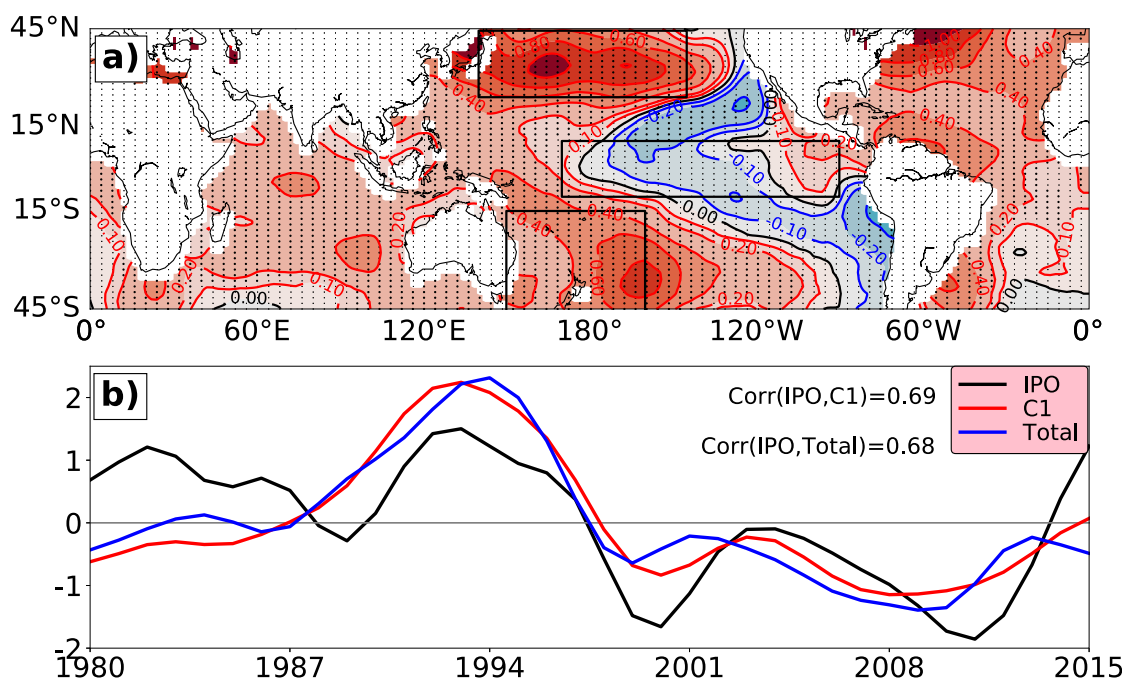

FIG. 6. (a) Composite differences in SST between the recent and prior periods and (b) time series of the IPO (black), the $\mathrm{C} 1$ (red), and total (blue) TC genesis frequencies, with the interannual variability removed using the nine-point Gaussian-type filter. In (a), areas where the differences are statistically significant at the $95 \%$ confidence level are shown in black dots based on the Student's $t$ test, and solid boxes indicate the three regions used to define the IPO. 
TABLE 1. Correlation coefficients between the IPO index and the genesis frequencies of total TCs and three cluster TCs for the prior period (1980-97), recent period (1998-2015), 1980-2015, and 1945-2015. “Corr” indicates interannual correlations with trends removed from the original data, and "Corr_filter" indicates interdecadal correlations with interannual variability removed from the original data. "No." indicates the number of TCs. The boldface values in "No." represent statistically significant differences in TC numbers between the recent and prior periods, and boldface correlation values (also marked with an asterisk) denote the correlations that are statistically significant at the $95 \%$ confidence level based on the Student's $t$ test.

\begin{tabular}{|c|c|c|c|c|c|c|c|c|}
\hline & \multicolumn{2}{|c|}{ Prior (1980-97) } & \multicolumn{2}{|c|}{ Recent (1998-2015) } & \multicolumn{2}{|c|}{ 1980-2015 } & \multicolumn{2}{|c|}{$1945-2015$} \\
\hline & No. & Corr & No. & Corr & Corr & Corr_filter & Corr & Corr_filter \\
\hline Total & 384 & -0.24 & 316 & -0.12 & -0.17 & $0.68 *$ & 0.09 & $0.52 *$ \\
\hline $\mathrm{C} 1$ & 123 & $0.59 *$ & 47 & $0.72 *$ & $0.63 *$ & $0.69 *$ & $0.63 *$ & $0.75^{*}$ \\
\hline $\mathrm{C} 2$ & 127 & $-0.73 *$ & 133 & $-0.45^{*}$ & $-0.67 *$ & -0.38 & $-0.4^{*}$ & -0.36 \\
\hline $\mathrm{C} 3$ & 134 & -0.25 & 136 & -0.13 & -0.1 & -0.08 & -0.18 & -0.002 \\
\hline
\end{tabular}

OLR anomaly to its south (Fig. 8a). In contrast, in the recent period, the monsoon trough weakened and shrank to the west of $140^{\circ} \mathrm{E}$ with the west-east positive OLR anomaly to it south (Fig. 8b), a situation unfavorable for TC genesis over the southeastern WNP. It means that the negative IPO phase can weaken the WNP monsoon trough and thus suppress $\mathrm{C} 1 \mathrm{TC}$ genesis in the southeastern WNP.

We performed regression analysis to further address this issue here. Note that the regression analyses were conducted with respect to the reverse (negative) IPO index. The large-scale atmospheric circulation anomaly associated with the negative IPO regressed based on the NCEP-NCAR reanalysis data includes the increased sea level pressure (SLP) (Fig. 9a), an anomalous broad anticyclonic circulation over the eastern WNP (Fig. 9b), the increased tropical easterly south of $15^{\circ} \mathrm{N}$ (Fig. 9b) linked to the strengthening of Walker circulation, anticyclonic vorticity anomalies both south of $15^{\circ} \mathrm{N}$ and over the northeast quadrant of the WNP (Fig. 9c), and the enhanced VZWS over the southeastern WNP (Fig. 9d).
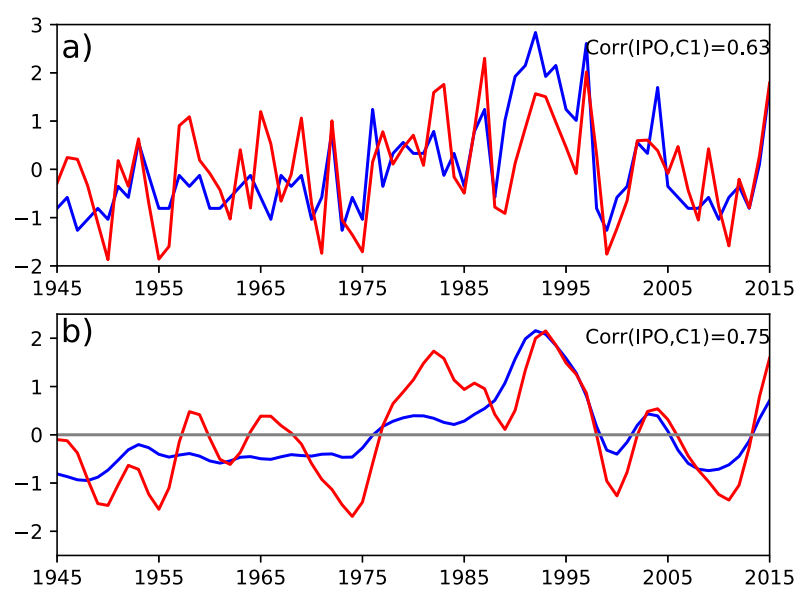

FIG. 7. The normalized time series of (a) unfiltered and (b) filtered IPO index (red) and C1 TC genesis frequency (blue) during 1945-2015.
As shown in Fig. 10, the regressed patterns derived from the ERA-Interim data are in general consistent with those shown in Fig. 9 based on the NCEP-NCAR reanalysis data. This suggests that the regression results did not significantly depend on the reanalysis data used.

The circulation anomalies associated with the negative IPO phase shown in Figs. 9 and 10 mainly suppressed TC genesis over the southeast quadrant of the WNP, namely, the genesis of C1 TCs (Figs. 3 and 5). Similar circulation anomalies have been found over the WNP in response to the global warming hiatus (Kosaka
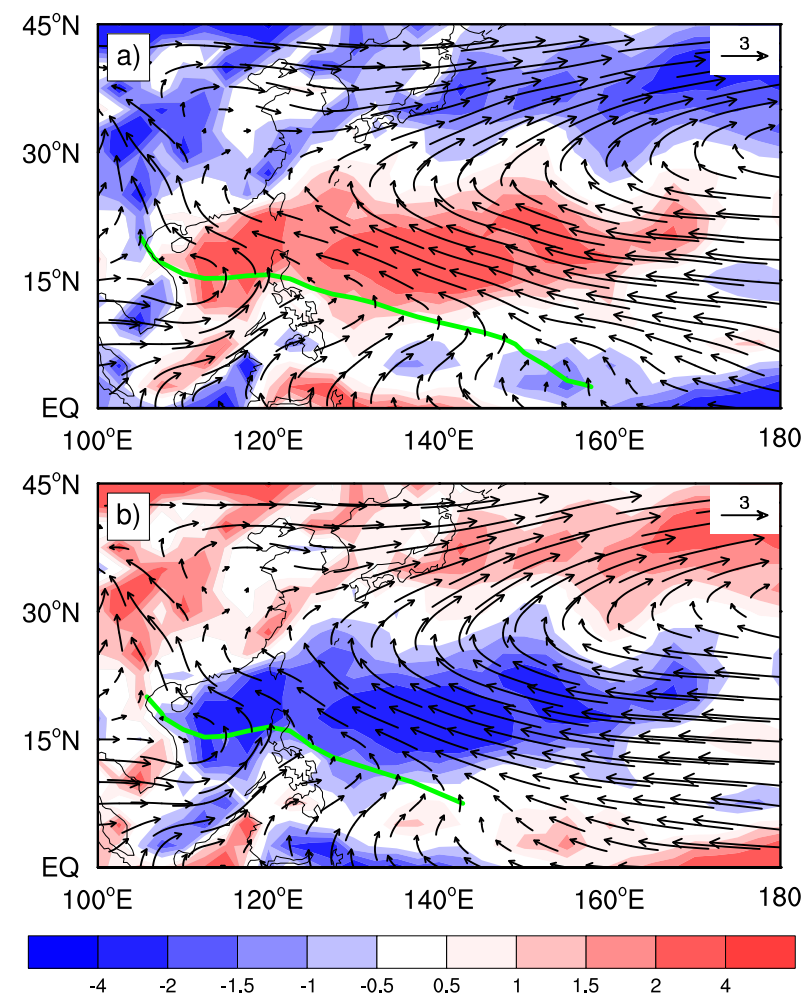

FIG. 8. Seasonal mean $850-\mathrm{hPa}$ winds (vector; $\mathrm{m} \mathrm{s}^{-1}$ ) and OLR anomalies (shaded; $\mathrm{W} \mathrm{m}^{-2}$ ) in the typhoon season for the (a) prior and (b) recent periods, respectively. 

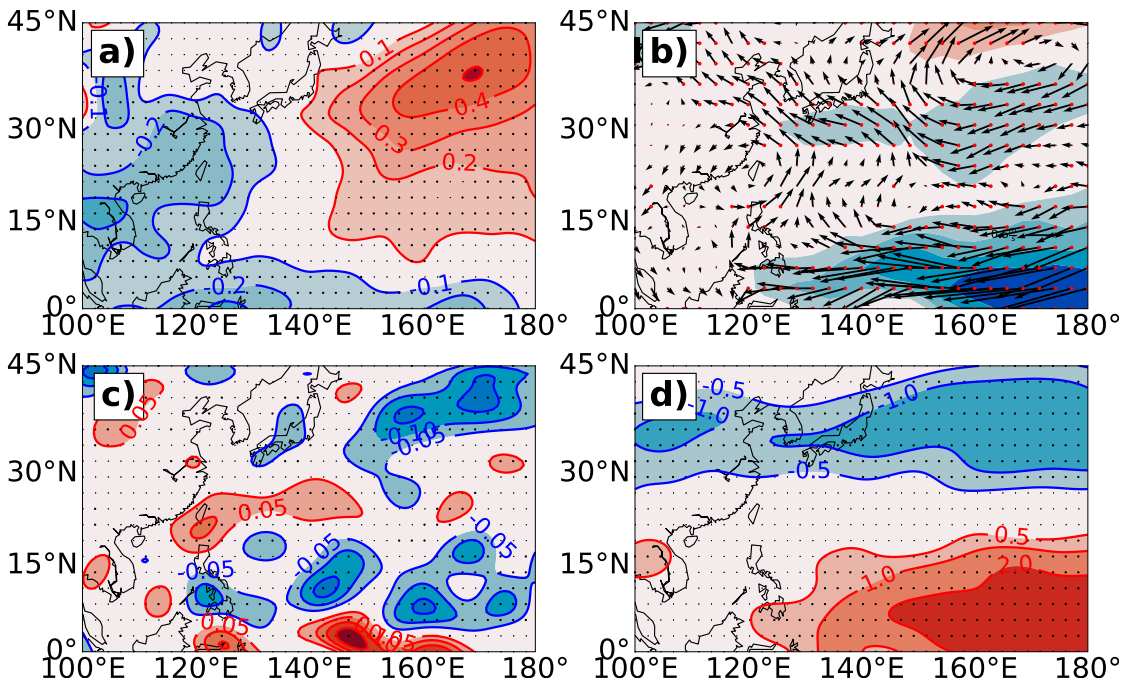

FIG. 9. The regressed atmospheric circulation fields based on the NCEP-NCAR reanalysis data with respect to the reversed (negative) IPO index with the interannual variability removed using a nine-point Gaussian filter in the typhoon season for 1980-2015. (a) Sea level pressure (SLP; $\mathrm{hPa}$ ), (b) 850-hPa horizontal winds (vectors; $\mathrm{m} \mathrm{s}^{-1}$ ) and zonal winds (shaded; $\mathrm{m} \mathrm{s}^{-1}$ ), (c) relative vorticity at $850 \mathrm{hPa}\left(10^{-5} \mathrm{~s}^{-1}\right)$, and (d) vertical zonal wind shear (VZWS; $\mathrm{m} \mathrm{s}^{-1}$ ). The dots represent areas where the regressed fields are statistically significant at the $95 \%$ confidence level using the Student's $t$ test after the degree of freedom is adjusted. In (b), the zonal winds greater (less) than $0.5(-0.5) \mathrm{m} \mathrm{s}^{-1}$ are shaded in blue (red).

and Xie 2013; Meehl et al. 2013, 2016; England et al. 2014; Douville et al. 2015) and the intensified megaENSO (Zhan and Wang 2017). Since these SSTA patterns show quite similar coherent spatial patterns, we thus consider that most of the interdecadal variability over the Pacific basin is linked to the IPO. This indeed supports some of the recent studies that reported that the recent negative IPO phase strengthened the Walker circulation (McGregor et al. 2014; Douville et al. 2015) and the poleward migration of the annual average location of TC lifetime maximum intensity over the WNP (Song and Klotzbach 2018). In this study, we show that the IPO mainly suppressed the genesis of C1 TCs only.

To further demonstrate the robustness of the impact of the IPO on the atmospheric circulation that largely controls C1 TC activity over the WNP discussed above
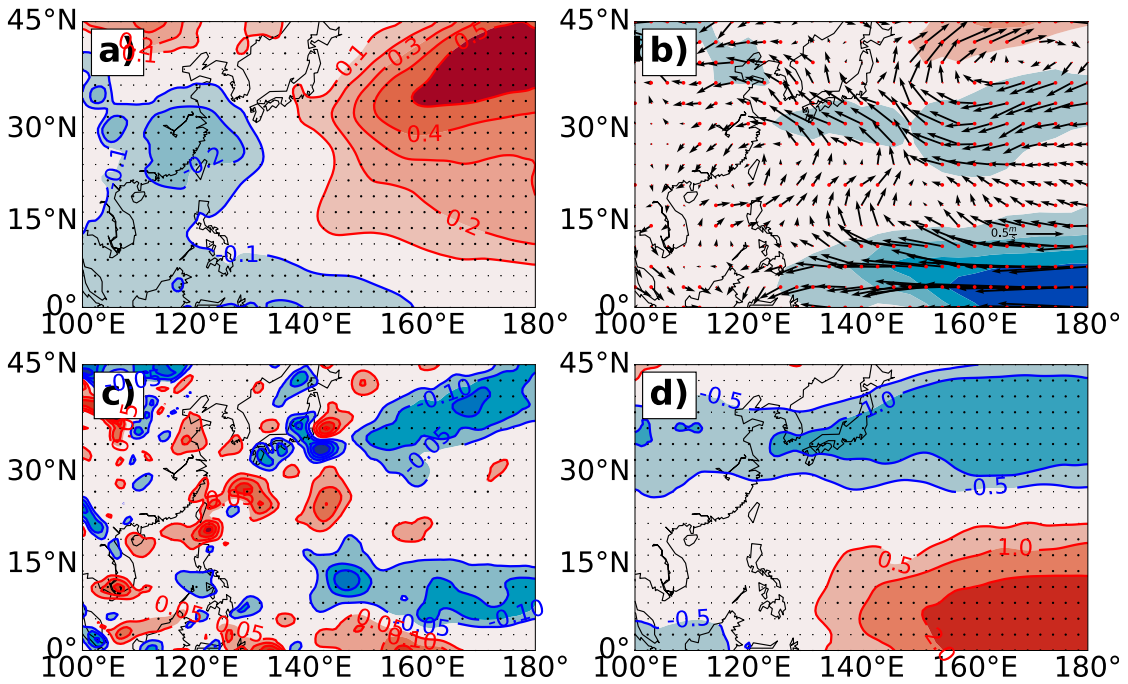

FIG. 10. As in Fig. 9, but using ERA-Interim data. 


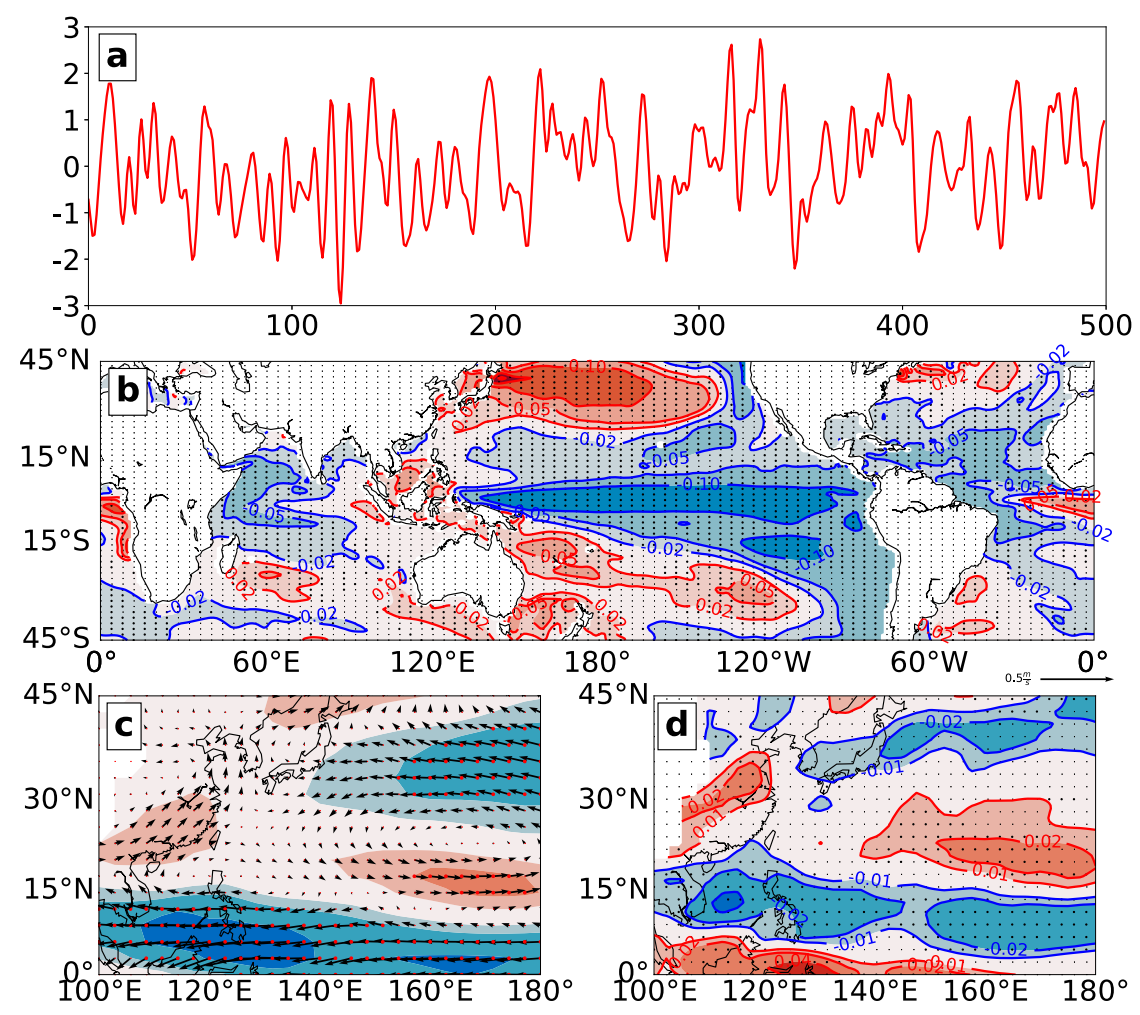

FIG. 11. (a) The IPO index derived from the 500-yr prehistorical experiment of the GFDL CM3 with the interannual variability removed using the nine-point Gaussian-type filter and (b)-(d) the regressed fields with respect to the reversed (negative) IPO index: (b) SSTA $\left({ }^{\circ} \mathrm{C}\right)$, (c) $850-\mathrm{hPa}$ horizontal winds (vectors; $\mathrm{m} \mathrm{s}^{-1}$ ) and zonal winds (shaded; $\mathrm{m} \mathrm{s}^{-1}$ ), and (d) $850-\mathrm{hPa}$ relative vorticity $\left(10^{-5} \mathrm{~s}^{-1}\right)$. Areas that are statistically significant at the $95 \%$ confidence level are denoted by dots based on the Student's $t$ test after the degree of freedom is adjusted. In (c), the zonal winds greater (less) than $0.1(-0.1) \mathrm{m} \mathrm{s}^{-1}$ are shaded in blue (red).

based on reanalysis data, we further analyzed the IPO index in the output of a 500-yr preindustrial experiment from the GFDL CM3. Figure 11a displays the IPO index based on the model output using the same definition of Henley et al. (2015) with the interannual variability removed. The regressed SSTA pattern associated with the negative IPO phase shows positive SSTAs over the subtropics and negative SSTAs over the tropics (Fig. 11b). This pattern is very similar to that in Fig. 6a based on observations for the period 1980-2015 except that the model-simulated negative SSTA in the equatorial Pacific penetrated too far toward the west, a wellknown bias in current coupled climate models (Xie et al. 2007). Nevertheless, the regressed patterns in low-level winds and vorticity fields (Figs. 11c and 11d) are quite similar to those in Figs. 9b (Fig. 10b) and 9c (Fig. 10c) based on reanalysis data. Namely, in the negative (positive) IPO phase, the tropical easterly associated with Walker circulation is strengthened (weakened) with negative (positive) vorticity anomalies over the southeastern WNP, thus suppressing (enhancing) genesis of
C1 TCs. The results from the coupled general circulation model experiment further confirm that it is the large-scale circulation anomalies associated with the recent negative IPO phase that suppressed C1 TC genesis over the southeastern WNP, which dominated the abrupt decrease in TC genesis frequency over the WNP since 1998.

An additional issue is whether the decrease in $\mathrm{C} 1 \mathrm{TC}$ genesis frequency occurred in the whole typhoon season or in any particular month(s) in the recent period. To address this issue we compared the monthly distribution of the identified C1 TCs in the two periods (Fig. 12). We can see that many more $\mathrm{C} 1$ TCs formed during AugustOctober than in June-July in the prior period, with the peak in October. The monthly genesis frequency of $\mathrm{C} 1$ TCs decreased during the whole typhoon season in the recent period compared to that in the prior period. The decrease is more pronounced during August-October, with the largest decrease in October. This is mainly because the WNP monsoon trough weakened and shifted westward in the recent period compared to that in 


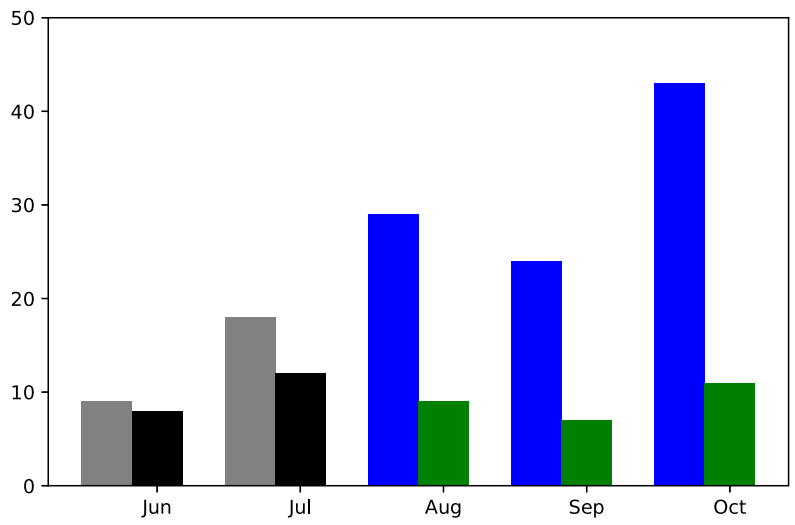

FIG. 12. The monthly distribution of genesis frequency of C1 TCs in the prior (gray and blue bars) and in the recent (black and green bars) periods. The blue and green bars represent the difference between the recent and prior periods significant at the $95 \%$ confidence level based on the Student's $t$ test.

the prior period (Fig. 8). We found that the weakening and westward shift of the WNP monsoon trough shown in Fig. 8 was largely contributed to by the weakening and westward shift in August-October, with the largest contribution from October (figure not shown). The results thus indicate that the significant decrease in $\mathrm{C} 1 \mathrm{TC}$ genesis frequency in the recent period was dominated by the decrease during August-October, with the largest decrease in October.

\section{Conclusions and discussion}

In this study, we have found that the abrupt decrease in WNP TC genesis frequency around 1998 was dominated by the sharp decrease of one cluster of TCs (C1) that mostly formed over the southeastern WNP, south of $15^{\circ} \mathrm{N}$ and east of Philippines. The sharp decrease of $\mathrm{C} 1$ TCs is found to be closely linked to the recent negative phase of the IPO. The other two clusters of TCs (C2 mainly formed north of $15^{\circ} \mathrm{N}$, and $\mathrm{C} 3$ formed mainly west of $145^{\circ} \mathrm{E}$ and over the SCS) are found to have contributed little to the interdecadal change of the total TC genesis frequency. Results from regression analyses show that the atmospheric circulation anomaly associated with the negative IPO phase is the strengthened tropical easterly with low-level anticyclonic vorticity anomalies and the increased VZWS in the southeastern WNP, significantly suppressing C1 TC genesis. Further analyses with the data extended back to 1945 and with the output of a 500-yr preindustrial general circulation model experiment from the GFDL CM3 further confirmed that it is the $\mathrm{C} 1 \mathrm{TCs}$ that largely contributed to the interdecadal change of the total TC genesis frequency over the WNP, and that it is the atmospheric circulation anomaly associated with the IPO that dominantly controlled the interdecadal change of the $\mathrm{C} 1 \mathrm{TC}$ genesis frequency. In contrast, the thermodynamic conditions including ocean conditions and moisture field played minor roles in this interdecadal change since they were favorable for TC genesis and intensification in the whole WNP basin as indicated in previous studies (e.g., Zhan and Wang 2017; Hu et al. 2018).

Our additional analysis indicated that more $\mathrm{C} 1 \mathrm{TCs}$ formed during August-October than in June-July in the prior period and it is the decrease in the $\mathrm{C} 1 \mathrm{TC}$ genesis frequency during August-October that dominated the decrease in $\mathrm{C} 1 \mathrm{TCs}$ in the recent period, with the largest decrease in October. We found that the weakening and westward shift of the WNP monsoon trough in the recent period (Fig. 8) was largely contributed to by the weakening and westward shift during August-October, with the greatest contribution from October.

The use of the objective clustering method in this study helped the identification of $\mathrm{C} 1 \mathrm{TCs}$ that dominated the interdecadal abrupt decrease in the total TC genesis frequency over the WNP around 1998 and facilitated identifying factors that predominantly contributed to the regional dependence of the interdecadal change of TC activity over the WNP. Because C3 TCs include TCs formed over the SCS and the western WNP south of $30^{\circ} \mathrm{N}$ (Fig. 3e), although a significant decrease in TC genesis and tracks appeared over the SCS (Fig. 2), the decrease did not show in C3 TCs because of the offset by an increase over the northern SCS and the western WNP (Fig. 2). Furthermore, although C2 TC genesis frequency did not show any significant interdecadal change, both $\mathrm{C} 1$ and $\mathrm{C} 2 \mathrm{TC}$ tracks experienced a westward shift during the recent period (Fig. 3), mainly due to a westward shift of the WNP subtropical high (figure not shown). We argue that if the IPO changes its current negative phase to a positive phase, which seemed to have already happened in the past several years (Fig. 6b), we may expect an increase of $\mathrm{C} 1 \mathrm{TCs}$ and thus an increase in TC genesis over the WNP.

It should be noted that previous studies have also mentioned the possible impact of the La Niña-like SSTA pattern on the abrupt decrease in WNP TC genesis frequency after 1998 (He et al. 2015; Hu et al. 2018). However, the involved physical mechanisms were not fully addressed. Hu et al. (2018) considered TCs over the WNP as a whole and pointed out that the VZWS induced by the La Niña-like SSTA pattern played a critical role in the interdecadal variability of TC genesis frequency. However, the VZWS change could not explain TC genesis over the entire WNP basin, and the low-level circulation over the WNP linked to the IPO is also important. In addition, $\mathrm{He}$ et al. (2015) also 
attributed the decrease in WNP TC genesis frequency to SSTAs in the tropical Indian Ocean. In fact, many recent studies based on observations and modeling experiments have suggested that the contribution of tropical Indian Ocean SSTAs to the interdecadal variability of TC genesis frequency over the WNP is very marginal (Yu et al. 2016; Zhao et al. 2018), although their contribution to the interannual variability of WNP TC genesis frequency is significant.

Finally, previous studies have found a southeastnorthwest shift of TC genesis location during different ENSO phases (Wang and Chan 2002; Zhan et al. 2011a; Bai et al. 2018). Furthermore, several previous studies have also indicated a northwestward shift in the mean TC genesis location and an east-west difference in TC genesis during October-December before and after the mid-1990s (Choi et al. 2015; Choi et al. 2017). Additionally, we also separated the WNP into two subregions: the southern region $\left(0^{\circ}-15^{\circ} \mathrm{N}, 120^{\circ} \mathrm{E}-180^{\circ}\right)$ and the northern region $\left(15^{\circ}-40^{\circ} \mathrm{N}, 120^{\circ} \mathrm{E}-180^{\circ}\right)$. We calculated the correlation coefficients between the IPO index and the TC genesis frequencies over the two subregions on the interdecadal time scale. Results show that a significant (an insignificant) correlation exists between the IPO and the TC genesis frequency over the southern (northern) region, with the correlation coefficient of $0.88(-0.24)$, consistent with our results based on cluster analysis that the IPO mainly controls the interdecadal variability of TC activity over the southeastern WNP, namely dominated by the variability of $\mathrm{C} 1 \mathrm{TCs}$. Note that although the correlation coefficient based on the subregions is slightly higher than that based on cluster analysis, the latter also reflected the predominant tracks in addition to the genesis locations.

Acknowledgments. This work has been supported by the National Natural Science Foundation of China (Grants 41375093, 41575052, and 41775060). Jiuwei Zhao acknowledges China Scholarship Council (File 201608320175) for the financial support. The JTWC best track TC data are available from http://www.metoc.navy. mil/jtwc/jtwc.html?best-tracks. The monthly mean SST data are from https://www.esrl.noaa.gov/psd/data/gridded/ data.noaa.ersst.v4.html. The GFDL Coupled Model data are available from http://nomads.gfdl.noaa.gov:8080/ DataPortal/cmip5.jsp. The NCEP-NCAR reanalysis I data are obtained from https://www.esrl.noaa.gov/psd/data/ gridded/data.ncep.reanalysis.html. The unfiltered tripole index data for the IPO are downloaded from https:// www.esrl.noaa.gov/psd/data/timeseries/IPOTPI/. The clustering model for TCs is available from http://www. datalab.uci.edu/resources/CCT.

\section{REFERENCES}

Bai, C., R. Zhang, S. Bao, X. San Liang, and W. Guo, 2018: Forecasting the tropical cyclone genesis over the Northwest Pacific through identifying the causal factors in cyclone-climate interactions. J. Atmos. Oceanic Technol., 35, 247-259, https:// doi.org/10.1175/JTECH-D-17-0109.1.

Bretherton, C. S., M. Widmann, V. P. Dymnikov, J. M. Wallace, and I. Bladé, 1999: The effective number of spatial degrees of freedom of a time-varying field. J. Climate, $\mathbf{1 2}$, 1990-2009, https://doi.org/10.1175/1520-0442(1999)012<1990: TENOSD $>2.0 . \mathrm{CO} ; 2$.

Camargo, S. J., and A. H. Sobel, 2005: Western North Pacific tropical cyclone intensity and ENSO. J. Climate, 18, 29963006, https://doi.org/10.1175/JCLI3457.1.

- - A. W. Robertson, S. J. Gaffney, P. Smyth, and M. Ghil, 2007a: Cluster analysis of typhoon tracks. Part I: General properties. J. Climate, 20, 3635-3653, https://doi.org/10.1175/ JCLI4188.1.

,,,,---- and $-2007 \mathrm{~b}$ : Cluster analysis of typhoon tracks. Part II: Large-scale circulation and ENSO. J. Climate, 20, 3654-3676, https://doi.org/10.1175/JCLI4203.1.

Cao, X., S. Chen, G. Chen, and R. Wu, 2016: Intensified impact of northern tropical Atlantic SST on tropical cyclogenesis frequency over the western North Pacific after the late 1980s. Adv. Atmos. Sci., 33, 919-930, https://doi.org/10.1007/ s00376-016-5206-z.

Chia, H. H., and C. F. Ropelewski, 2002: The interannual variability in the genesis location of tropical cyclones in the northwest Pacific. J. Climate, 15, 2934-2944, https://doi.org/ 10.1175/1520-0442(2002)015<2934:TIVITG > 2.0.CO;2.

Choi, J. W., Y. Cha, T. Kim, and H. D. Kim, 2017: Interdecadal variation of tropical cyclone genesis frequency in late season over the western North Pacific. Int. J. Climatol., 37, 4335-4346, https://doi.org/10.1002/joc.5090.

Choi, Y., K. J. Ha, C. H. Ho, and C. E. Chung, 2015: Interdecadal change in typhoon genesis condition over the western North Pacific. Climate Dyn., 45, 3243-3255, https://doi.org/10.1007/ s00382-015-2536-y.

Dee, D. P., and Coauthors, 2011: The ERA-Interim reanalysis: Configuration and performance of the data assimilation system. Quart. J. Roy. Meteor. Soc., 137, 553-597, https://doi.org/ 10.1002/qj.828.

Donner, L. J., and Coauthors, 2011: The dynamical core, physical parameterizations, and basic simulation characteristics of the atmospheric component AM3 of the GFDL global coupled model CM3. J. Climate, 24, 3484-3519, https://doi.org/10.1175/ 2011JCLI3955.1.

Douville, H., A. Voldoire, and O. Geoffroy, 2015: The recent global warming hiatus: What is the role of Pacific variability? Geophys. Res. Lett., 42, 880-888, https://doi.org/10.1002/ 2014 GL062775.

Emanuel, K. A., 1999: Thermodynamic control of hurricane intensity. Nature, 401, 665-669, https://doi.org/10.1038/ 44326.

England, M. H., and Coauthors, 2014: Recent intensification of wind-driven circulation in the Pacific and the ongoing warming hiatus. Nat. Climate Change, 4, 222-227, https://doi.org/ 10.1038/nclimate2106.

Gaffney, S. J., A. W. Robertson, P. Smyth, S. J. Camargo, and M. Ghil, 2007: Probabilistic clustering of extratropical cyclones using regression mixture models. Climate Dyn., 29, 423-440, https://doi.org/10.1007/s00382-007-0235-z. 
Harr, P. A., and R. L. Elsberry, 1991: Tropical cyclone track characteristics as a function of large-scale circulation anomalies. Mon. Wea. Rev., 119, 1448-1468, https://doi.org/10.1175/ 1520-0493(1991)119<1448:TCTCAA > 2.0.CO;2.

$\longrightarrow$, and — 1995: Large-scale circulation variability over the tropical western North Pacific. Part II: Persistence and transition characteristics. Mon. Wea. Rev., 123, 1247-1268, https://doi.org/ 10.1175/1520-0493(1995)123<1247:LSCVOT>2.0.CO;2.

He, H., J. Yang, D. Gong, R. Mao, Y. Wang, and M. Gao, 2015: Decadal changes in tropical cyclone activity over the western North Pacific in the late 1990s. Climate Dyn., 45, 3317-3329, https://doi.org/10.1007/s00382-015-2541-1.

Henley, B. J., J. Gergis, D. J. Karoly, S. Power, J. Kennedy, and C. K. Folland, 2015: A tripole index for the Interdecadal Pacific Oscillation. Climate Dyn., 45, 3077-3090, https://doi.org/ 10.1007/s00382-015-2525-1.

Hong, C. C., Y. K. Wu, and T. Li, 2016: Influence of climate regime shift on the interdecadal change in tropical cyclone activity over the Pacific Basin during the middle to late 1990s. Climate Dyn., 47, 2587-2600, https://doi.org/10.1007/ s00382-016-2986-x.

Hsu, P.-C., P.-S. Chu, H. Murakami, and X. Zhao, 2014: An abrupt decrease in the late-season typhoon activity over the western North Pacific. J. Climate, 27, 4296-4312, https://doi.org/ 10.1175/JCLI-D-13-00417.1.

Hu, F., T. Li, J. Liu, M. Bi, and M. Peng, 2018: Decrease of tropical cyclone genesis frequency in the western North Pacific since 1960s. Dyn. Atmos. Oceans, 81, 42-50, https://doi.org/10.1016/ j.dynatmoce.2017.11.003.

Huang, B., and Coauthors, 2015: Extended reconstructed sea surface temperature version 4 (ERSST.v4). Part I: Upgrades and intercomparisons. J. Climate, 28, 911-930, https://doi.org/ 10.1175/JCLI-D-14-00006.1.

Huangfu, J., R. Huang, W. Chen, T. Feng, and L. Wu, 2017: Interdecadal variation of tropical cyclone genesis and its relationship to the monsoon trough over the western North Pacific. Int. J. Climatol., 37, 3587-3596, https://doi.org/ 10.1002/joc.4939.

,$- \ldots$, and,- 2018 : Interdecadal variation of tropical cyclone genesis and its relationship to the convective activities over the central Pacific. Climate Dyn., 50, 1439-1450, https:// doi.org/10.1007/s00382-017-3697-7.

Jin, F.-F., 1997: An equatorial ocean recharge paradigm for ENSO. Part I: Conceptual model. J. Atmos. Sci., 54, 811-829, https://doi.org/10.1175/1520-0469(1997)054<0811: $\mathrm{AEORPF}>2.0 . \mathrm{CO} ; 2$.

Kalnay, E., and Coauthors, 1996: The NCEP/NCAR 40-Year Reanalysis Project. Bull. Amer. Meteor. Soc., 77, 437-471, https:// doi.org/10.1175/1520-0477(1996)077<0437:TNYRP>2.0.CO;2.

Kim, H.-K., and K.-H. Seo, 2016: Cluster analysis of tropical cyclone tracks over the western North Pacific using a selforganizing map. J. Climate, 29, 3731-3751, https://doi.org/ 10.1175/JCLI-D-15-0380.1.

Kosaka, Y., and S.-P. Xie, 2013: Recent global-warming hiatus tied to equatorial Pacific surface cooling. Nature, 501, 403-407, https://doi.org/10.1038/nature12534.

Lepage, Y., 1971: A combination of Wilcoxon's and AnsariBradley's statistics. Biometrika, 58, 213-217, https://doi.org/ 10.1093/biomet/58.1.213.

Li, W., L. Li, and Y. Deng, 2015: Impact of the interdecadal Pacific oscillation on tropical cyclone activity in the North Atlantic and Eastern North Pacific. Sci. Rep., 5, 12358, https://doi.org/ $10.1038 /$ srep12358
Liu, K. S., and J. C. L. Chan, 2013: Inactive period of western North Pacific tropical cyclone activity in 1998-2011. J. Climate, 26, 2614-2630, https://doi.org/10.1175/JCLI-D-12-00053.1.

McGregor, S., A. Timmermann, M. F. Stuecker, M. H. England, M. Merrifield, F.-F. Jin, and Y. Chikamoto, 2014: Recent Walker circulation strengthening and Pacific cooling amplified by Atlantic warming. Nat. Climate Change, 4, 888-892, https:// doi.org/10.1038/nclimate2330.

Meehl, G. A., A. Hu, J. M. Arblaster, J. Fasullo, and K. E. Trenberth, 2013: Externally forced and internally generated decadal climate variability associated with the interdecadal Pacific oscillation. J. Climate, 26, 7298-7310, https://doi.org/ 10.1175/JCLI-D-12-00548.1.

,,-- B. D. Santer, and S.-P. Xie, 2016: Contribution of the Interdecadal Pacific Oscillation to twentieth-century global surface temperature trends. Nat. Climate Change, 6, 10051008, https://doi.org/10.1038/nclimate3107.

Mei, W., and S.-P. Xie, 2016: Intensification of landfalling typhoons over the northwest Pacific since the late 1970s. Nat. Geosci., 9, 753-757, https://doi.org/10.1038/ngeo2792.

Power, S., T. Casey, C. K. Folland, A. Colman, and V. Mehta, 1999: Inter-decadal modulation of the impact of ENSO on Australia. Climate Dyn., 15, 319-323, https://doi.org/10.1007/ s003820050284.

Song, J., and P. J. Klotzbach, 2018: What has controlled the poleward migration of annual averaged location of tropical cyclone lifetime maximum intensity over the western North Pacific since 1961? Geophys. Res. Lett., 45, 1148-1156, https:// doi.org/10.1002/2017GL076883.

Sverdrup, H. U., 1947: Wind-driven currents in a baroclinic ocean; with application to the equatorial currents of the Eastern Pacific. Proc. Natl. Acad. Sci. USA, 33, 318-326, https:// doi.org/10.1073/pnas.33.11.318.

Takahashi, C., M. Watanabe, and M. Mori, 2017: Significant aerosol influence on the recent decadal decrease in tropical cyclone activity over the western North Pacific. Geophys. Res. Lett., 44, 9496-9504, https://doi.org/10.1002/ 2017GL075369.

Walsh, K. J. E., and Coauthors, 2016: Tropical cyclones and climate change. Wiley Interdiscip. Rev.: Climate Change, 7, 65-89, https://doi.org/10.1002/wcc.371.

Wang, B., and J. C. L. Chan, 2002: How strong ENSO events affect tropical storm activity over the western North Pacific. J. Climate, 15, 1643-1658, https://doi.org/10.1175/ 1520-0442(2002)015<1643:HSEEAT > 2.0.CO;2.

Wu, L., C. Wang, and B. Wang, 2015: Westward shift of western North Pacific tropical cyclogenesis. Geophys. Res. Lett., 42, 1537-1542, https://doi.org/10.1002/2015GL063450.

Xie, S.-P., and Coauthors, 2007: A regional ocean-atmosphere model for eastern Pacific climate: Toward reducing tropical biases. J. Climate, 20, 1504-1522, https://doi.org/10.1175/ JCLI4080.1.

Yu, J., T. Li, Z. Tan, and Z. Zhu, 2016: Effects of tropical North Atlantic SST on tropical cyclone genesis in the western North Pacific. Climate Dyn., 46, 865-877, https://doi.org/10.1007/ s00382-015-2618-x.

Zhan, R., and Y. Wang, 2017: Weak tropical cyclones dominate the poleward migration of the annual mean location of lifetime maximum intensity of Northwest Pacific tropical cyclones since 1980. J. Climate, 30, 6873-6882, https://doi.org/10.1175/ JCLI-D-17-0019.1.

, - and X. Lei, 2011a: Contributions of ENSO and East Indian Ocean SSTA to the interannual variability of 
Northwest Pacific tropical cyclone frequency. J. Climate, 24, 509-521, https://doi.org/10.1175/2010JCLI3808.1. , and C.-C. Wu, 2011b: Impact of SSTA in the East Indian Ocean on the frequency of Northwest Pacific tropical cyclones: A regional atmospheric model study. J. Climate, 24, 6227-6242, https://doi.org/10.1175/JCLI-D-10-05014.1.

_, _ - and M. Wen, 2013: The SST gradient between the southwestern Pacific and the western Pacific warm pool: A new factor controlling the northwestern Pacific tropical cyclone genesis frequency. J. Climate, 26, 2408-2415, https:// doi.org/10.1175/JCLI-D-12-00798.1.

_ _ _ and L. Tao, 2014: Intensified impact of East Indian Ocean SST anomaly on tropical cyclone genesis frequency over the western North Pacific. J. Climate, 27, 8724-8739, https://doi.org/10.1175/JCLI-D-14-00119.1.

, —, and J. Zhao, 2017: Intensified mega-ENSO has increased the proportion of intense tropical cyclones over the western Northwest Pacific since the late 1970s. Geophys. Res. Lett., 44, 11 959-11 966, https://doi.org/10.1002/2017GL075916.
Zhang, W., G. A. Vecchi, H. Murakami, G. Villarini, T. L. Delworth, X. Yang, and L. Jia, 2018: Dominant role of Atlantic Multidecadal Oscillation in the recent decadal changes in Western North Pacific tropical cyclone activity. Geophys. Res. Lett., 45, 354-362, https://doi.org/10.1002/2017GL076397.

Zhao, H., and C. Wang, 2016: Interdecadal modulation on the relationship between ENSO and typhoon activity during the late season in the western North Pacific. Climate Dyn., 47, 315-328, https://doi.org/10.1007/s00382-015-2837-1.

Zhao, J., R. Zhan, Y. Wang, and L. Tao, 2016: Intensified interannual relationship between tropical cyclone genesis frequency over the northwest Pacific and the SST gradient between the southwest Pacific and the western Pacific warm pool since the mid-1970s. J. Climate, 29, 3811-3830, https:// doi.org/10.1175/JCLI-D-15-0729.1.

,$- \ldots$, and -2018 : Global warming hiatus contributed to the increased occurrence of intense tropical cyclones in the coastal regions along East Asia. Sci. Rep., 8, 6023, https:// doi.org/10.1038/s41598-018-24402-2. 